\title{
INTERNATIONAL CENTRE FOR DIFFRACTION DATA CRYSTALLOGRAPHY SCHOLARSHIP AWARDS
}

The science of crystallography has played a key role in the development of $\mathrm{X}$-ray diffraction, electron diffraction and neutron diffraction for the elucidation of the atomic structure of matter. Crystallography is an interdisciplinary branch of science taught in departments of physics, chemistry, geology, molecular biology, metallurgy and material science. To encourage promising graduate students to pursue crystallographically oriented research, the International Centre for Diffraction Data (ICDD) has established a Crystallography Scholarship Fund. While the Ewald Prize is awarded every 3 years to an internationally recognized crystallographer, little effort has been made by science departments to cultivate aspiring crystallographers. Convinced of the beneficial, scientific impact of the proposed scholarships for crystallographically oriented research, the ICDD has solicited funds from private and industrial sectors to support this program. The ICDD has awarded 2 scholarships in 1992, 2 in 1993, 3 in 1994, 3 in 1995, 4 in 1996, 4 in 1997 and 5 in 1998. Applications for the 1999 awards must be received by ICDD no later than 31 October 1998 .

Qualifications for the applicant: The applicant should be a graduate student seeking a degree with major interest in crystallography, e.g., crystal structure analysis, crystal morphology, modulated structures, correlation of atomic structure with physical properties, systematic classification of crystal structures, phase identification and materials characterization. There are no restrictions on country, race, age or sex. The term of the scholarship is 1 year. Application for 1 renewal may be made by the recipient at the end of the first year. Because a limited number of scholarships are awarded, renewal applications will be considered on a competitive basis in conjunction with all applications that have been submitted up to the closing date.
Submit:

- Curriculum Vitae, listing degree(s) held and degree(s) sought.

- A 1-page proposal by the graduate student describing the type of crystallographic research to be partially supported by scholarship.

- A supportive letter from the sponsoring professor of an accredited university or an institute of technology on institution letterhead.

Restrictions on the scholarship fund:

- The scholarship stipend of $\$ 2,000$ is to be used by the graduate student to help defray tuition and laboratory fees. A portion of the stipend may be applied to registration fees to accredited scientific meetings related to crystallography.

- No more than 1 scholarship will be awarded to applicants at any 1 accredited institution per year.

- The funds of the scholarship are not to be used for travel.

The awarding of the scholarships is administered by a committee consisting of the ICDD Chairman, the Chairman of the ICDD Technical Committee, the Chairman of the ICDD Education Subcommittee and 1 or 2 individuals without conflict of interest. One or more accredited professors (with no conflicts of interest) may be invited to assist in the selection of successful candidates.

Applications must be received by 31 October 1998. Please mail to:

\author{
Secretary \\ International Centre for Diffraction Data \\ 12 Campus Boulevard \\ Newtown Square, PA 19073-3273 U.S.A.
}

